\title{
Treatment of Hepatitis B in Decompensated Liver Cirrhosis
}

\author{
Richard Guan ${ }^{1}$ and Hock Foong Lui ${ }^{2}$ \\ ${ }^{1}$ Mount Elizabeth Hospital and Medical Centre, Singapore 228510 \\ ${ }^{2}$ Gleneagles Hospital and Medical Centre, Singapore 258500 \\ Correspondence should be addressed to Richard Guan,rgyc5@singnet.com.sg \\ Received 15 February 2011; Accepted 19 April 2011 \\ Academic Editor: Deepak Amarapurkar
}

Copyright ( 2011 R. Guan and H. F. Lui. This is an open access article distributed under the Creative Commons Attribution License, which permits unrestricted use, distribution, and reproduction in any medium, provided the original work is properly cited.

Chronic hepatitis B infection progresses from an asymptomatic persistently infected state to chronic hepatitis, cirrhosis, decompensated liver disease, and/or hepatocellular carcinoma. About 3\% of patients with chronic hepatitis develop cirrhosis yearly, and about $5 \%$ of individuals with hepatitis B cirrhosis become decompensated annually. The outcome for patients with decompensated cirrhosis is bleak. Lamivudine, the first oral antiviral agent available for hepatitis B treatment is safe and effective and can improve or stabilize liver disease in patients with advanced cirrhosis and viraemia. Viral resistance restricts its prolonged use. Entecavir and tenofovir are newer agents with excellent resistance profile to date. These and some other antiviral agents are being investigated for optimal use in this rather challenging patient group.

\section{Introduction}

Chronic hepatitis B virus (HBV) infection is a major global public health problem with an estimated 1 million deaths yearly worldwide from complications of liver cirrhosis namely, liver failure and hepatocellular cancer (HCC) $[1,2]$. Up to $40 \%$ patients with chronic hepatitis B virus infection develop serious complications during their lifetime. Up to $12 \%$ of patients with HBV cirrhosis die of liver failure, and up to $10 \%$ perish from liver cancer $[3,4]$. The prognosis for patients with decompensated HBV cirrhosis is poor, with a 5 -year survival of only $14 \%$ compared with $84 \%$ in patients with compensated HBV cirrhosis [3]. The ultimate cure for end stage liver disease is liver transplantation. Many patients with advanced hepatitis B worldwide do not have access to or are not eligible for this treatment modality $[1,5]$. This article briefly review the epidemiology and natural progression of chronic hepatitis B infection and provides an update on the medical management of patients with decompensated HBV cirrhosis with particular emphasis on the use of available antiviral agents.

\section{Prevalence of Hepatitis B Infection}

Hepatitis B virus (HBV) infection is endemic in the Asia Pacific region and in Africa. Up to $62 \%$ of the population in China, up to $98 \%$ of the people in sub-Saharan Africa and up to $80 \%$ of the populations in some Pacific islands have markers of HBV infection [6]. Chronic or persistent HBV infection is defined as the presence of hepatitis B surface antigen (HBsAg) in the serum for longer than 6 months. It is estimated that there are 350 million people with chronic HBV infection worldwide (more than 5\% of the world population). More than $75 \%$ of these chronically infected people live in Asia and a further 12\%, (approximately 50 million) live in Africa. In many countries in the Asia Pacific region, $8-20 \%$ of the populations have chronic HBV infection [7].

\section{Disease Progression in Chronic Hepatitis B Infection}

Chronic HBV infection can lead to chronic liver disease, with a broad range of symptoms $[8,9]$. The early phase of the infection is typically asymptomatic with active virus replication (HBVDNA > 20,000 IU/mL) and very little liver necroinflammation. Hepatitis B antigen (HBeAg) is present. This phase, also called the immune-tolerant phase, can last for several decades before the appearance of hepatitis symptoms. Persistent or episodic hepatic necroinflammation (chronic hepatitis), with elevated serum alanine 
aminotransferase (ALT) levels, characterizes this phase of immune elimination of HBV. During this stage, HBeAg and HBV DNA levels may progressively decrease and seroconversion from $\mathrm{HBeAg}$ to $\mathrm{HBe}$ antibody (anti-HBe) may occur $[10,11]$. The longer this period of active liver disease lasts, the higher the risk of irreversible liver damage. Patients enter the third (inactive carrier) phase when HBV replication is no longer detected and liver histology usually stabilizes [10]. However low levels of the virus (HBVDNA < $2000 \mathrm{IU} / \mathrm{mL}$ ) can stillbe detected in the majority of patients, and reactivation of $\mathrm{HBV}$ replication with exacerbation of disease can occur [12-14]. Some patients may progress to cirrhosis and HCC during this phase of apparent inactivity.

In the Asia-Pacific region, the annual incidence of chronic hepatitis in asymptomatic, persistently infected individuals ranged from 0.84 to $2.7 \%$. The annual incidence of cirrhosis among patients with chronic hepatitis B was reported to be approximately $1.0-2.4 \%$. The annual rates of progression from compensated cirrhosis to decompensated cirrhosis were around $4.6 \%[15,16]$. The annual incidence of HCC ranged from $0.02-0.65 \%$ in asymptomatic persistently infected individuals, $0.27-1.0 \%$ in patients with chronic hepatitis B and 3.0-6.6\% in compensated HBV cirrhosis [6]. The annual progression rate from decompensated HBV cirrhosis to HCC was around 7.1\%. The 5-year mortality rate from decompensated cirrhosis was from $41 \%$ to $67 \%$ $[17,18]$.

Factors associated with rapid disease progression in $\mathrm{HBV}$ infected patients include the male gender, increasing age, viraemia with repeated hepatic flares or prolonged periods of liver necroinflammation, and alcohol use; confection with other viruses such as hepatitis $\mathrm{C}$, hepatitis D, and human immunodeficiency virus (HIV); use of immunosuppressive agents, platelets less than $150,000 / \mathrm{mL}$ and serum bilirubin more than $1.1 \mathrm{mg} / \mathrm{dL}$ (18.8 umol/L) [19-26]. Patients with HBV cirrhosis and active viral replication are at increased risk of developing progressive liver disease and death $[4,27]$. Loss of HBeAg and seroconversion to HBe antibody (anti$\mathrm{HBe}$ ) with reduction in HBVDNA levels have been associated with a $55 \%$ reduction in the risk of death [3]. Suppression of $\mathrm{HBV}$ replication with loss of $\mathrm{HBeAg}$ and or $\mathrm{HBsAg}$ is therefore an important event in the natural history and treatment of chronic HBV infection.

\section{Liver Cirrhosis and Decompensation}

The mean age of onset of cirrhosis in chronic HBV infection acquired during childhood, is about 40 years and complications become clinically evident 3 to 5 years later. It is estimated that the annual rate of hepatic decompensation is $4 \%$ in cirrhotic patients with viraemia and $1 \%$ in those without viraemia [14]. The development of jaundice, ascites, hepatic encephalopathy (HE) or bleeding oesophageal varices signals decompensation. Acute decompensation is usually secondary to a hepatitis flare or spontaneous bacterial infection which further impairs the already decreased hepatic reserve. The other form is a gradually developing end-stage event. As mentioned previously, the outlook for decompensated cirrhosis is rather bleak with a 5-year survival of $14 \%$ compared with $84 \%$ in patients with compensated cirrhosis [3].

\section{General Management of Patients with Decompensated Liver Cirrhosis}

5.1. Assessment of Disease Severity. Clinical examination and measurement of blood parameters like serum albumin, bilirubin, creatinine and prothrombin time can help determine the severity and progression of liver disease. The ChildTurcotte-Pugh (CTP) score and Model for End Stage Liver Disease (MELD) score are two indices that are usually used to determine the severity of liver disease in patients with cirrhosis [28] (Table 1). The CTP score was developed to determine preoperative risk of patients with cirrhosis for portal-systemic shunt surgery. It is calculated by adding the individual scores assigned to ranges of serum albumin level, serumbilirubin level, prothrombin time, the presence and degree of ascites and hepatic encephalopathy. The CTP score is easily calculated at the patient's bedside. The MELD score was initially developed to predict short-term mortality following transjugular intrahepatic portosystemic shunt (TIPS) placement. It was later modified to predict short-term mortality in patients with different causes of cirrhosis [28] and is now being used to predict waiting list mortality of patients listed for liver transplantation. The MELD score uses objective and standardized laboratory parameters (i.e., serum bilirubin, prothrombin time (international normalized ratio, INR), and creatinine) over a broader range of possible values to provide a more dynamic assessment of liver disease severity. Calculating the MELD score needs a calculator and cannot be easily done at the patient's bedside.

5.2. Prevent Further Liver Damage. Alcohol, potentially hepatotoxic drugs including medications that may increase the risk of gastrointestinal bleeding (nonsteroidal antiinflammatory agents), or renal insufficiency should be avoided. Patients with decompensated HBV cirrhosis should be vaccinated against hepatitis $A$ if not already immune as superimposed hepatitis A infection could be fatal [29, 30]. As mentioned, the presence of HBeAg or HBV DNA indicates continuing viral replication. International guidelines suggest treating patients with chronic hepatitis B cirrhosis if serum HBV DNA present (EASL) or more than 2,000 IU/mL (AASLD/APASL). The threshold for antiviral therapy is usually lower for decompensated liver disease [31-33].

5.3. Prevent and Treat Complications of Cirrhosis. Gastroscopy should be performed on initial presentation and every two years afterwards in patients with liver cirrhosis to look for oesophageal and gastric varices [34]. If these are found, appropriate treatment should be instituted. Variceal bleeding can be prevented in grade 3 and 4 varices by oral beta blockers and endoscopicvariceal ligation [35]. Treatment of variceal bleeding should include antibiotics to prevent spontaneous septicaemia. Transjugular intrahepatic portosystemic stent (TIPS) placement may be required in patients with uncontrolled or recurrent variceal bleeding 
TABle 1: Assessing liver disease severity in decompensated HBV cirrhosis.

\begin{tabular}{lcccc}
\hline Scale (range) & Mild & Moderate & Severe & Ref. \\
\hline CTP (5 to 15) & $5-6(\mathrm{~A})$ & $7-9(\mathrm{~B})$ & $10-15(\mathrm{C})$ & $\begin{array}{c}\text { Keeffe, 2001 } \\
{[43]}\end{array}$ \\
MELD (6-40) & $6-10$ & $11-24$ & $25-40$ & $\begin{array}{c}\text { Kamath et al., } \\
2001[28]\end{array}$ \\
\hline
\end{tabular}

[36]. TIPS may also be considered in patients with refractory ascites if their liver function is not severely impaired, if they are less than 70 years old, and if hepatic encephalopathy is absent [37]. Spontaneous bacterial peritonitis (SBP) and other spontaneous infections should be treated straight away with broad spectrum antibiotics, (e.g., cephalosporins or amoxicillin/clavulanate) and albumin to prevent the hepatorenal syndrome [38]. Prophylactic antibiotics should be given to patients with a history of SBP [39].

Hepatic encephalopathy is a severe complication of cirrhosis and is related to the effect of ammonia. Recent evidence suggests that the effect of ammonia on the brain is triggered by inflammation caused by spontaneous infections. The mainstay of therapy is antibiotics (neomycin, rifaximin, vancomycin) and nonabsorbable disaccharides. Protein restriction is no longer recommended and can worsen the nutritional status if maintained [40]. The development of HE in patients with cirrhosis is associated with a less than $50 \%$ survival at 1 year. Liver transplant should be considered. Hepatorenal syndrome (HRS) is a potentially lethal complication and is usually triggered by infections. Besides antibiotics, it can be effectively treated with vasoconstrictors associated with intravenous albumin, TIPS, and albumin dialysis [41] .

5.4. HCC Surveillance. Patients should undergo HCC surveillance by determining serum alpha-fetoprotein (AFP) levels and liver ultrasound every 6 months [32] (Table 2). Early stage HCC can be successfully managed by locoregional ablative therapy [42] and may change the priority for transplantation [43].

\section{Liver Transplantation}

Liver transplantation is a well-established modality for treating patients with advanced irreversible liver failure for which there are no alternative treatments [43]. Approximately 5\% of liver transplants performed in the United States annually are for hepatitis B [44], and the proportion is higher in the Asia Pacific region [33]. All cirrhotic patients with a CTP score of more than 7 and a complication of portal hypertension such as ascites, encephalopathy, or variceal bleeding should be referred for liver transplant evaluation [43]. Selected patients with unresectable HCC that is less than $5 \mathrm{~cm}$ in maximal diameter should also be referred for liver transplant evaluation.

Immunoprophylaxis using prolonged high-dose hepatitis B immunoglobulin (HBIG) has resulted in excellent patient and graft survival rates for patients with decompensated
HBV cirrhosis who were viraemic pretransplant $[5,45]$. Up to $40 \%$ of patients with pretransplant viraemia who received HBIG alone developed recurrent HBV infection [5]. This risk of posttransplant HBV recurrence can be reduced by antiviral suppression of HBV replication prior to transplantation and maintenance of antiviral therapy after transplantation [33]. Liver transplantation is not available to many patients with decompensated HBV infection in the Asia Pacific region, and the only recourse for these patients is antiviral therapy.

\section{Antiviral Treatment}

Suppression of HBV replication has resulted in reduction of hepatic necroinflammation and improvement of liver function in patients with $\mathrm{CHB}$ cirrhosis and liver decompensation. Patients with decompensated HBV-cirrhosis should be considered for antiviral therapy irrespective of HBVDNA levels.

7.1. Interferon-Alpha. Interferon-alpha or its pegylated version is safe and effective in patients with chronic hepatitis $\mathrm{B}$ and in selected patients with compensated HBV cirrhosis $[46,47]$. It has been associated with life-threatening hepatitis flares (up to 50\%) and infectious complications (28\%) in prospective trials of patients with decompensated HBV cirrhosis even when used in very low doses $[48,49]$. It is generally discouraged in patients with decompensated HBV cirrhosis.

7.2. Oral Antiviral Agents. Most practice guidelines recommend prescribing an oral nucleos(t)ide analogue (and not interferon) for patients with decompensated HBV cirrhosis independent of the patients serum ALT, HBV DNA level, and $\mathrm{HBeAg}$ status [31-33]. These recommendations are largely based upon open-label studies of lamivudine and adefovir in this group of patients. These studies reported that antiviral therapy was associated with improved outcomes including a delay or prevention in the need for liver transplantation (Table 1) [50-53]. A biphasic survival pattern was noted with most deaths occurring within the first 6 months of treatment; patients with higher pretreatment bilirubin, creatinine, and HBV DNA levels were at greatest risk for early death while early suppression of HBV replication was not associated with more favorable outcomes [51].

\section{Lamivudine}

Lamivudine is an orally administered nucleoside analogue that inhibits HBVDNA synthesis by incorporating active triphosphate (3TC-TP) into growing DNA chains. It suppressed serum HBV DNA to undetectable levels (using hybridization assays) in more than $90 \%$ of patients with compensated chronic hepatitis B. This was associated with improved serum ALT levels as well as liver histology at 12 months $[54,55]$. It is generally safe and well tolerated with a side effect profile similar to that of placebo [54], making it the preferred treatment compared to IFN for patients with 
Table 2: General Recommendations in Decompensated HBV Cirrhosis.

\begin{tabular}{|c|c|}
\hline Assess disease severity & Clinical, liver biochemistry, creatinine, INR CTP score, MELD score \\
\hline \multirow{5}{*}{ Prevent further liver damage } & Avoid alcohol \\
\hline & Avoid hepatotoxic drugs \\
\hline & Avoid Immunosuppression. Antiviral prophylaxis if necessary \\
\hline & Avoid Aspirin/NSAIDS \\
\hline & Hepatitis A vaccination in nonimmune \\
\hline Prevent and treat & Laboratory and clinical assessment 3 to 6 monthly \\
\hline \multirow{7}{*}{ Complications } & Endoscopy at presentation and treat varices accordingly \\
\hline & Be aware of spontaneous infections and treat appropriately \\
\hline & Salt and fluid restriction in ascites control, TIPS \\
\hline & Albumin and terlipressin in hepatorenal syndrome \\
\hline & Antibiotics and nonabsorbable disaccharides in hepatic encephalopathy \\
\hline & Low-protein diet not essential \\
\hline & Regular AFP measurement and ultrasound examination \\
\hline \multirow{5}{*}{ Antiviral therapy } & Entecavir \\
\hline & $\begin{array}{l}\text { Lamivudine. Replace with entecavir monotherapy, Tenofovir monotherapy, or add on adefovir in } \\
\text { cases of lamivudine resistance }\end{array}$ \\
\hline & Tenofovir \\
\hline & Telbivudine \\
\hline & Adefovir \\
\hline Liver transplantation & $\begin{array}{l}\text { Pretransplant antiviral therapy in viraemic subjects and immunoprophylaxis using HBIG after } \\
\text { transplant }\end{array}$ \\
\hline
\end{tabular}

decompensated HBV cirrhosis. Hepatitis flares during treatment usually indicate the occurrence of resistant mutations. The recommended dose of lamivudine is $100 \mathrm{mg}$ daily. Dose modification is necessary in renal impairment (reduction) and in patients with HIV coinfection (increment). Once treatment is initiated, it should be maintained indefinitely even in patients who appear to have dramatic clinical improvement and in those undergoing liver transplantation.

Development of lamivudine resistance begins after 6 months of treatment, and up to $70 \%$ of patients become lamivudine resistant after 5 years of continuous therapy [32]. Resistance to lamivudine is manifested by the reappearance of HBV DNA after its initial suppression with a variable increase in serum ALT levels $[55,56]$. The most common mutation involves the YMDD motif of the HBV polymerase gene (M204V/I) and is frequently accompanied by another mutation in an upstream region (L180M) [57]. Diagnostic assays for lamivudine-resistant mutants are commercially available. Hepatitis flares are not uncommon with the emergence of YMDD mutants resulting in progressive worsening of liver disease $[58,59]$ and can be fatal in patients with decompensated disease.

Lamivudine resulted in a rapid suppression of $\mathrm{HBV}$ DNA to undetectable levels (non-PCR-based assays) and improvement in biochemical and clinical parameters in both controlled and uncontrolled studies of patients with decompensated HBV cirrhosis [51, 60-65]. Twenty-three out of 35 decompensated HBV patients treated by Villeneuve and colleagues showed a slow but marked improvement in biochemical parameters and CTP scores [60]. Seven patients underwent liver transplantation, and 5 patients died within the first 6 months of lamivudine treatment. Two of these 23 patients later perished (from SBP and HCC, resp.) and 3 developed lamivudine resistance.

Significant improvement in CTP scores (8.3 versus 6.7) and ALT levels (111 versus $58 \mathrm{IU} / \mathrm{L})$ were also noted in 18 Indians with decompensated HBV cirrhosis after a mean treatment duration of 18 months using lamivudine [61]. Yao and Bass reported similar CTP score improvement in 13 patients with Child's $\mathrm{C}$ cirrhosis given lamivudine and 5 of the patients were eventually taken off the liver transplant waiting list [62]. Similar findings were also noted in 30 Greek patients with decompensated HBV cirrhosis given lamivudine [63].

More than $80 \%$ of 154 patients with decompensated HBV cirrhosis had suppression of HBV DNA to undetectable levels by the branched-chain DNA (bDNA) assay within 8 weeks of initiating lamivudine treatment by Fontana and coworkers [51]. HBeAg loss was seen in 35\% patients and $\mathrm{HBeAg}$ seroconversion to anti-HBe occurred in $20 \%$ of patients. The actuarial 3-year survival was $72 \%$ for all patients and $88 \%$ for patients who survived beyond the first 6 months of treatment.

In a study involving $77 \mathrm{HBsAg}$-positive liver transplant candidates, Perrillo et al. reported stabilization or improvement in liver disease severity with lamivudine in 27 patients without transplants who were treated with lamivudine for a median of 28 months [64]. The actuarial survival in these patients appeared to be better than the survival in untreated historical controls with decompensated HBV cirrhosis and 
similar to that of patients with untreated compensated HBV cirrhosis from an earlier observation [3].

Yao et al. noted that transplant candidates receiving lamivudine were less likely to undergo transplantation than untreated historical controls who were matched for age, gender, and illness severity at the time of listing (35\% versus $74 \%, P=.04$ ) [65]. A significantly greater proportion of the lamivudine-treated patients experienced an improvement $\geq 3$ points in their CTP scores compared with the untreated historical controls (61\% versus $0 \%, P=.0001)$. In a retrospective analysis of 309 North American HBsAg positive liver transplant candidates, Fontana and his colleagues compared the outcomes of 162 lamivudine-treated patients and 147 untreated patients [66]. The two groups were comparable in liver disease severity before treatment. Treated patientswere more likely to have evidence of active HBV replication. Overall, the actuarial pretransplant and transplant-free survival was similar in the two groups and lamivudine had no apparent effect on liver disease severity in patients who underwent transplantation. However, among the patients who were still awaiting transplantation, lamivudine appeared to stabilize or improve liver disease severity.

Earlier studies using lamivudine in decompensated HBV cirrhosis were not controlled, and control cohorts used in later studies were either historical or non-randomised. Inclusion criteria and therapeutic endpoints were also inhomogeneous. It was unclear whether patients in some of the studies had acute hepatic decompensation secondary to a recent hepatitis flare as improvement upon viral suppression is more likely in group than in patients with hepatic decompensation secondary to end-stage liver disease $[60,61]$. Other interventions that may have prolonged transplantfree survival (e.g., TIPS, use of prophylactic antibiotics) may have contributed to the observed improvements in clinical outcomes. In spite of all these inadequacies, lamivudine was found to be safe in patients with decompensated HBV cirrhosis although not all patients benefited from it [67]. Clinical improvement usually occurs between 3 to 6 months of therapy and improvement might not occur if treatment is started late. Pretreatment severity of liver disease (increased bilirubin, low albumin, prolonged PT and raised creatinine) is a more important predictor of early mortality than antiviral response in this group of patients [51, 66]. Careful monitoring is mandatory in patients with decompensated liver disease treated with lamivudine as a hepatitis flare from resistant mutants can be fatal. Should molecular resistance be detected add on therapy with adefovir dipivoxil or substitution therapy with tenofovir or entecavir is advised. Patients with initial clinical improvement can develop complications of cirrhosis and HCC even in the absence of lamivudineresistance.

\section{Adefovir Dipivoxil}

Adefovir dipivoxil is a prodrug of adefovir, an acyclic nucleotide analog of adenosine monophosphate. Adefovir is phosphorylated to the active metabolite, adefovir diphosphate, by cellular kinases. Adefovir diphosphate inhibits HBV DNA polymerase (reverse transcriptase) by competing with the natural substrate deoxyadenosine triphosphate and by causing DNA chain termination after its incorporation into viral DNA [33]. It has a high genetic barrier to resistance and has the ability to suppress most lamivudine-resistant mutants. Renal toxicity is rare with the dose of $10 \mathrm{mg}$ daily (Table 3 ). Adefovir dipivoxil has been available for the treatment of chronic hepatitis B since 2003 but has not been evaluated as a primary treatment for patients with decompensated cirrhosis.

In a compassionate use study involving 128 patients with decompensated cirrhosis and 196 patients with recurrent hepatitis B after liver transplant, addition of adefovir resulted in a 3-4 $\log 10$ reduction in serum HBVDNA levels, which was sustained throughout the course of treatment [52]. After 48 weeks of treatment, undetectable HBV DNA by PCR and normal ALT was noted in $81 \%$ and $76 \%$ of the pretransplant and $34 \%$ and $49 \%$ of the posttransplant patients, respectively. More than $90 \%$ of the pretransplant patients had improvement in their CTP scores, and 1-year survival was $84 \%$ for the pre- and $93 \%$ for the posttransplant patients. Follow-up data on 226 pretransplant patients showed that viral suppression was maintained in $65 \%$ of patients after 96 weeks of treatment with accompanying improvement in CTP and MELD scores. Fourteen percent of patients died within the first year and at least 33\% required liver transplantation for long-term survival [53].

A recent interim report showed no difference in mortality rates after 24 weeks of treatment in 195 patients with decompensated HBV cirrhosis randomized to adefovir or entecavir. This study is in progress [68].

Although antiviral drug resistance is substantially less common with adefovir monotherapy compared to lamivudine, concerns remain regarding the slow rate of suppressing HBV replication with adefovir as well as the potential for dose-dependent nephrotoxicity in decompensated HBV patients (up to $28 \%$ of patients had an increase in serum creatinine $\geq 0.5 \mathrm{mg} / \mathrm{dL}$ after 48 weeks of treatment $[69,70]$. Until more data becomes available, adefovir should not be recommended as first-line treatment in patients with decompensated HBV-cirrhosis. However, for patients with worsening liver disease secondary to lamivudine resistance, use of adefovir as a salvage therapy is an option.

\section{Telbivudine}

Telbivudine, a synthetic thymidine nucleoside analogue, is active against HBV. It undergoes phosphorylation by cellular enzymes to form the active metabolite, telbivudine triphosphate which incorporates into viral DNA competing with the natural substrate, thymidine triphosphate, and causing DNA chain termination, resulting in inhibition of HBV replication. It has demonstrated potent activity against hepatitis B with a significantly higher rate of response and superior viral suppression compared with lamivudine and adefovir [71]. It is generally well tolerated with a low adverse effect. It was approved by the FDA in late 2006. HBV strains with reduced susceptibility to telbivudine have emerged during therapy with the drug. Cross-resistance may 
TABLe 3: Antiviral Agents with Activity against Wild Type and Lamivudine resistant HBV.

\begin{tabular}{lccc}
\hline Agent & Daily dose & Side effects & Comments \\
\hline Adefovir & $10 \mathrm{mg}$ & Dose-dependant nephrotoxicity & Drug resistance after 12 months \\
Entecavir & $1 \mathrm{mg}$ & No major side effects to date & Drug resistance eventually in lamivudine-resistant mutants \\
Tenofovir & $300 \mathrm{mg}$ & Neuropathy, nausea, CPK elevations, Fanconi syndrome & No drug resistance up to 4 years \\
\hline
\end{tabular}

occur among some nucleoside analogues active against HBV. Lamivudine-resistant HBV with reduced susceptibility to telbivudine has been observed. Some adefovir-resistant HBV are also resistant to telbivudine.

Gane and colleagues conducted a double blind trial on 195 patients (70\% Asians) with decompensated HBV liver disease [72]. Patients were randomly assigned to receive $600 \mathrm{mg}$ telbivudine or $100 \mathrm{mg}$ lamivudine for 104 weeks. About three-quarters were men, with a mean age of 52 years and 57\% were HBeAg negative. In a 2-year intent-totreat analysis, more patients appeared to have undetectable HBV DNA (<300 copies/mL; 47\% versus $36 \%, P=.15$ ) and ALT normalization ( $58 \%$ versus $50 \%, P=.25$ ) in the telbivudine treatment arm than in the lamivudine arm. Using a composite endpoint of undetectable HBV DNA and ALT normalization, however, telbivudine performed significantly better than lamivudine (34\% versus 24\%, resp.; $P=.004$ ). $29 \%$ of telbivudine recipients experienced viral breakthrough while on therapy, compared with 39\% of lamivudine recipients $(P=.16)$. At the end of treatment, about $75 \%$ of patients in both arms had stabilized or improved liver disease, as indicated by changes from baseline in CTP scores. Kidney function (indicated by glomerular filtration rate) modestly improved in the telbivudine arm, while worsening in the lamivudine arm. Early (week 24) survival rates were similar in the 2 study arms, 96\% with telbivudine and $92 \%$ with lamivudine. Long-term (week 104) survival rates were $96 \%$ and $83 \%$, respectively, with a trend toward statistical significance. Serious adverse events were common, consistent with advanced liver disease, and they occurred with similar frequency in both arms (55\% of telbivudine recipients versus $61 \%$ of lamivudine recipients). No cases of rhabdomyolysis or lactic acidosis were reported. The investigators concluded that telbivudine was well tolerated with stabilization of liver function and had comparable tolerability to lamivudine.

\section{Entecavir}

Entecavir is a cyclopentyl guanosine analogue with potent selective inhibition of the priming, DNA-dependent synthesis, and reverse transcription functions of HBV polymerase. It has demonstrated activity against both wildtype HBV and, to a lesser extent, lamivudine-resistant $\operatorname{HBV}[73,74]$. It suppresses HBV replication more rapidly and effectively than lamivudine or adefovir in patients with compensated chronic $\mathrm{HBV}[75,76]$. It has an excellent resistance profile after 5 years in nuycleosid(t)e naïve patients and does not have any reported nephrotoxicity [77], It has been used to rescue a small number of liver transplant recipients with lamivudineresistant HBV successfully [78].
Shim et al. demonstrated that $0.5 \mathrm{mg}$ entecavir daily was effective in treating 70 nucleoside naïve decompensated HBV patients with nearly 90\% achieving undetectable HBV DNA (PCR) at 1 year [79]. The virological responses in 55 decompensated HBV patients treated for at least 1 year were compared to 144 compensated patients treated with entecavir from the same center. The mean MELD (11.5 versus 7 ) and CTP scores (8.1 versus 5.3 ) were significantly higher in the decompensated patients. The proportion of HBeAg positive patients and mean HBV DNA levels were similar in the two groups. Overall, the 1-year transplantfree survival rate was $87 \%$ in the decompensated patients. As seen previously with lamivudine, the majority of adverse outcomes occurred during the first 6 months of therapy with the nine patients having more severe liver failure at entry. Baseline HBV DNA levels, HBe antigenaemia and response to therapy were similar in both survivors and non-survivors or those who underwent transplant. Nearly $50 \%$ of the entecavir treated patients had a clinically significant decrease in their CTP score of $>2$ points at 1 -year. HBeAg loss in both the decompensated and compensated patients was remarkably high at 1 year (48\% vs $41 \%$ ). HBV DNA suppression was maintained during followup with no instances of viral rebound or entecavir-resistant HBV. Not all decompensated patients improved with entecavir therapy. Twelve patients $(22 \%)$ showed no change in their CTP score at 1-year (4 patients had aggravation or their liver disease with worsening CTP scores). Five patients developed HCC during followup.

A retrospective analysis of 107 decompensated patients (mean age 53 years; $70.1 \%$ men; $42 \% \mathrm{HBeAg}$ positive) treated with lamivudine or entecavir showed significantly lower serum HBV DNA levels and prevalence of patients with undetectable HBV DNA (PCR) at 3, 6, 9, and 12 months after treatment in entecavir-treated patients than in the lamivudine group. Serum ALT levels, CTP and MELD score, and the prevalence of patients with improved CTP scores at 3, 6, 9, and 12 months did not differ between two groups. The prevalence of HBeAg seroconversion and HCC and mortality also did not differ between two groups while that of viral breakthrough was significantly more frequent in the lamivudine-treated patients [80].

Liaw et al. randomized 195 patients with decompensated HBV to entecavir ( $1.0 \mathrm{mg}$ per day) or aderovir (10 mg per day) [68], One-third (34\%) of patients had lamivudineresistant $\mathrm{HBV}$. Interim results at week 24 demonstrated a significantly greater reduction in HBV DNA and serum ALT levels in the entecavir treated patients. The 24 week mortality rates were similar in both treatment arms. Entecavir was well tolerated and safety results were comparable in both treatment groups. Continued followup is needed since the rate of 
entecavir-resistant HBV can substantially increase over time in lamivudine-resistant HBV infection and potentially fatal flares may develop [81].

Entecavir was recently compared with tenofovir + emtricitabine combination and tenofovir singly in an ongoing multicentre study [82]. Improvements in CTP and MELD scores as well as frequency of undetectable HBV DNA at week 48 were similar in the three treatment arms.

Severe lactic acidosis with entecavir has been reported in patients with decompensated liver [83].

\section{Tenofovir}

Tenofovir is an acyclic nucleotide analog with a molecular structure similar to that of adefovir. It is approved for the treatment of HIV infection and has in vitro activity against both wild type and lamivudine-resistant HBV [84]. It is administered as the prodrug tenofovir disoproxil fumarate (TDF), and it is converted to tenofovir by plasmaesterases. Tenofovir is phosphorylated to the active metabolite which works as a chain terminator if incorporated into the DNA chain and is a competitive inhibitor of natural deoxyadenosine 50-triphosphate. Tenofovir is eliminated by a combination of glomerular filtration and active tubular secretion. It is a significantly more potent suppressor of HBV replication than adefovir and no drug-resistant variants have been reported with 4 years of continuous treatment in compensated HBV patients [85].

In the ongoing study reported in the previous section [84], on 112 decompensated HBV patients given tenofovir, tenofovir + emtricitabine, or entecavir, there were more undetectable HBV DNA at week 48 in the tenofovir containing treatment arms $(71 \%)$ than in the entecavir treatment arm $(33 \%)$ in patients with lamivudine resistant HBV. HBeAg seroconversion was seen in $21 \%$ and $13 \%$ of the tenofovir and tenofovir/emtricitabine arms, respectively, but not in the entecavir arm. Rates of nephrotoxicity, tolerability and patient mortality were similar in the three treatment arms through week 48 . Continued follow-up of these patients is needed to determine which of the newer antiviral agents can offer the best risk-benefit ratio in this challenging patient population.

Although a tenofovir-based regimen may be preferred in decompensated patients with lamivudine-resistant HBV, there are concerns regarding the long-term safety of tenofovirin some HBV patients including nephrotoxicity and metabolic bone disease [86, 87]. Patients with decompensated cirrhosis are frequently malnourished and may have low vitamin D levels. Prospective studies of bone density and metabolic parameters during prolonged tenofovir treatment are warranted as well as potential calcium and vitamin $\mathrm{D}$ supplementation [88].

\section{Summary}

The availability of safe, orally administered antiviral agents has revolutionized the management of chronic HBV and opened up new treatment options for the large number of patients with decompensated HBV cirrhosis worldwide who previously had a dismal prognosis. These drugs can improve or stabilize liver disease in patients who are not transplant candidates or have no access to liver transplantation. For these patients, the oral HBV antivirals may represent the only hope for better quality or longer duration of survival and reduced utilization of health care resources. The aim of treatment in transplant candidates is to improve their functional status such that they eventually might be removed from the transplantation list. All patients with decompensated cirrhosis, regardless of their serum HBV DNA level, should be considered for treatment. Decompensated patients with evidence of active $\mathrm{HBV}$ replication (i.e., presence of $\mathrm{HBe}$ antigenemia and HBV DNA $>2000 \mathrm{iu} / \mathrm{mL}$,) are more likely to derive benefit from antiviral therapy.

Clinical studies have confirmed that oral antivirals are generally safe and effective in suppressing HBV replication in decompensated HBV cirrhosis with resultant stabilization or improvement in liver disease. Clinical improvement is slow and takes 3 to 6 months. It is not certain if starting treatment earlier will improve the rate of response. Recent efficacy and safety data supports the use of entecavir as a first-line treatment option for nucleos $(\mathrm{t})$ ide naive patients with decompensated HBV cirrhosis [89]. Lamivudine and telbivudine are also safe agents, but the risk of resistance with prolonged therapy is ever present with potential for worsening liver disease and increased risk of HBV recurrence after transplantation and vigilance is important. Tenofovir or entecavir monotherapy or adefovir add-on therapy are possible rescue options should resistance occur. Studies evaluating tenofovir monotherapy and combination therapy in patients with decompensated cirrhosis are in progress. However, continued follow-up from these ongoing studies including long-term efficacy, safety, and resistance data are needed. Further studies are also needed to identify the optimal agent(s) for patients with decompensated lamivudine-resistant HBV cirrhosis. Decompensated HBV patients receiving oral nucleos $(\mathrm{t}) \mathrm{lde}$ analogues must undergo frequent clinical and laboratory assessment to insure medication compliance and surveillance for vIrological and clinical response as well as drug side effects, drug resistance, and HCC. As it is not possible to identify which patients with high CTP or MELD scores will have poor short term prognosis, it is advisable to refer all decompensated HBV patients for liver transplant evaluation at presentation if available.

Antiviral therapy should be given to all potential liver transplant candidates with decompensated HBV cirrhosis and detectable HBV-DNA. Lamivudine resistance will result in HBV recurrence in the posttransplant period [33]. Adefovir and entecavir can be given to rescue lamivudine resistance, and initial use of these agents may minimize drug resistance. Lamivudine plus low-dose intramuscular HBIg (400-800 U daily for 1 week, then monthly) is as effective as lamivudine plus high-dose intravenous HBIg in preventing recurrent $\mathrm{HBV}$ infection resulting in a 5-year graft survival of up to $85 \%$ at $10 \%$ of the cost [90]. Substituting HBIg with adefovir 12 months posttransplant also prevent late HBV recurrence and costs much less [91]. Lamivudine plus adefovir combination from the time of listing has been shown to be well tolerated, prevent lamivudine resistance 
prior to transplant, rescued some patients from the need for transplantation, and prevented recurrent $\mathrm{HBV}$ infection following liver transplantation, regardless of baseline HBVDNA status [92]. Patients who were HBV-DNA negative prior to transplant and those with sustained protective levels of anti-HBs following posttransplant vaccination can be safely given lamivudine or entecavir monotherapy 12 months after transplant. Antiviral prophylaxis should also be given in patients who have received an anti-HBc(+) liver to prevent de novo HBV infection.

Although the outlook for decompensated HBV patients is bright with the advent of these oral antivirals, emphasis should be placed on effective treatment of patients with chronic HBV infection to prevent them from progressing to the decompensated state.

\section{References}

[1] E. E. Mast, M. J. Alter, and H. S. Margolis, "Strategies to prevent and control hepatitis $\mathrm{B}$ and $\mathrm{C}$ virus infections: a global perspectiveStrategies to prevent and control hepatitis $\mathrm{B}$ and $\mathrm{C}$ virus infections: a global perspective," Vaccine, vol. 17, no. 1314, pp. 1730-1733, 1999.

[2] G. M. McQuillan, P. J. Coleman, D. Kruszon-Moran, L. A. Moyer, S. B. Lambert, and H. S. Margolis, "Prevalence of hepatitis B virus infection in the United States: the National Health and Nutrition examination surveys, 1976 through 1994," American Journal of Public Health, vol. 89, no. 1, pp. 14-18, 1999.

[3] F. E. De Jongh, H. L. A. Janssen, R. A. De Man, W. C. J. Hop, S. W. Schalm, and M. Van Blankenstein, "Survival and prognostic indicators in hepatitis B surface antigen-positive cirrhosis of the liver," Gastroenterology, vol. 103, no. 5, pp. 1630-1635, 1992.

[4] G. Fattovich, L. Brollo, G. Giustina et al., "Natural history and prognostic factors for chronic hepatitis B," Gut, vol. 32, no. 3, pp. 294-298, 1991.

[5] D. Samuel, R. Muller, G. Alexander et al., "Liver transplantation in European patients with the hepatitis B surface antigen," New England Journal of Medicine, vol. 329, no. 25, pp. 18421847, 1993.

[6] X. M. Lin, N. Robinson, M. Thursz et al., "Chronic hepatitis $B$ virus infection in the Asia-Pacific region and Africa: review of disease progression," Journal of Gastroenterology and Hepatology, vol. 20, pp. 833-843, 2005.

[7] I. D. Gust, "Epidemiology of hepatitis B infection in the Western Pacific and South East Asia," Gut, vol. 38, supplement 2, no. 2, pp. S18-S23, 1996.

[8] A. S. Lok, "Natural history and control of perinatally acquired hepatitis B virus infection," Digestive Diseases, vol. 10, no. 1, pp. 46-52, 1992.

[9] D. S. Chen, "Natural history of chronic hepatitis B virusinfection: new light on an old story," Journal of Gastroenterology and Hepatology, vol. 8, pp. 470-475, 1993.

[10] C. M. Chu, P. Karayiannis, and M. J. F. Fowler, "Natural history of chronic hepatitis B virus infection in Taiwan: studies of hepatitis B virus DNA in serum," Hepatology, vol. 5, no. 3, pp. 431-434, 1985.

[11] E. R. Schiff, M. F. Sorrell, and W. C. Maddrey, Diseases of the Liver, Lippincott Williams \&Wilkins, Haggerstown, Md, USA, 8th edition, 1999.
[12] P. Marcellin, M. Martinot-Peignoux, M. A. Loriot et al., "Persistence of hepatitis B virus DNA demonstrated by polymerase chain reaction in serum and liver after loss of HBsAg induced by antiviral therapy," Annals of Internal Medicine, vol. 112, no. 3, pp. 227-228, 1990.

[13] S. Kaneko, R. H. Miller, A. M. Di Bisceglie, S. M. Feinstone, J. H. Hoofnagle, and R. H. Purcell, "Detection of hepatitis B virus DNA in serum by polymerase chain reaction: application for clinical diagnosis," Gastroenterology, vol. 99, no. 3, pp. 799804, 1990.

[14] C. M. Chu and Y. F. Liaw, "Hepatitis B virus-related cirrhosis: natural history and treatment," Seminars in Liver Disease, vol. 26, no. 2, pp. 142-152, 2006.

[15] B. Xu, D. C. Hu, D. M. Rosenberg et al., "Chronic Hepatitis B-a long term retrospective cohort study of disease progression in Shanghai, China," Journal of Gastroenterology and Hepatology, vol. 18, no. 12, pp. 1345-1352, 2003.

[16] Y. F. Liaw, D. Y. Lin, T. J. Chen, and C. M. Chu, "Natural course after the development of cirrhosis in patients with chronic type B hepatitis: a prospective study," Liver, vol. 9, no. 4, pp. 235-241, 1989.

[17] I. Okazaki, K. Maruyama, and K. Funatsu, “Ten year survival rate of 131 patients with liver cirrhosis excluded the association of liver carcinoma at the establishment of diagnosis," Gastroenterologia Japonica, vol. 15, no. 4, pp. 350-354, 1980.

[18] A. Y. Hui, H. L. Y. Chan, N. W. Y. Leung, L. C. T. Hung, F. L. Chan, and J. J. Y. Sung, "Survival and prognostic indicators in patients with hepatitis B virus-related cirrhosis after onset of hepatic decompensation," Journal of Clinical Gastroenterology, vol. 34, no. 5, pp. 569-572, 2002.

[19] F. Donato, A. Tagger, R. Chiesa et al., "Hepatitis B and C virus infection, alcohol drinking, and hepatocellular carcinoma: a case-control study in Italy," Hepatology, vol. 26, no. 3, pp. 579584, 1997.

[20] K. Krogsgaard, B. O. Lindhardt, and J. O. Nielsen, "The influence of HTLV-III infection on the natural history of hepatitis B virus infection in male homosexual HBsAg carriers," Hepatology, vol. 7, no. 1, pp. 37-41, 1987.

[21] V. K. Rustgi, J. H. Hoofnagle, and J. L. Gerin, "Hepatitis B virus infection in the acquired immunodeficiency syndrome," Annals of Internal Medicine, vol. 101, no. 6, pp. 795-797, 1984.

[22] Y. F. Liaw, "Role of hepatitis $\mathrm{C}$ virus in dual and triple hepatitis virus infection," Hepatology, vol. 22, no. 4 I, pp. 1101-1108, 1995.

[23] L. Benvegnu, G. Fattovich, F. Noventa et al., "Concurrent hepatitis B and $\mathrm{C}$ virus infection and risk of hepatocellular carcinoma in cirrhosis: a prospective study," Cancer, vol. 74, no. 9, pp. 2442-2448, 1994.

[24] G. Fattovich, G. Giustina, E. Christensen et al., "Influence of hepatitis delta virus infection on morbidity and mortality in compensated cirrhosis type B," Gut, vol. 46, no. 3, pp. 420426, 2000.

[25] R. Tur-Kaspa, Y. Shaul, D. D. Moore et al., "The glucocorticoid receptor recognizes a specific nucleotide sequence in hepatitis B virus DNA causing increased activity of the HBV enhancer," Virology, vol. 167, no. 2, pp. 630-633, 1988.

[26] J. S. McMillan, T. Shaw, P. W. Angus, and S. A. Locarnini, "Effect of immunosuppressive and antiviral agents on hepatitis B virus replication in vitro," Hepatology, vol. 22, no. 1, pp. 36-43, 1995.

[27] Y. F. Liaw, D. I. Tai, C. M. Chu, and T. J. Chen, "The development of cirrhosis in patients with chronic type $\mathrm{B}$ hepatitis: a prospective study," Hepatology, vol. 8, no. 3, pp. 493-496, 1988. 
[28] P. S. Kamath, R. H. Wiesner, M. Malinchoc et al., "A model to predict survival in patients with end-stage liver disease," Hepatology, vol. 33, no. 2, pp. 464-470, 2001.

[29] E. B. Keeffe, "Is hepatitis A more severe in patients with chronic hepatitis B and other chronic liver diseases?" American Journal of Gastroenterology, vol. 90, no. 2, pp. 201-205, 1995.

[30] Centers for Disease Control and Prevention, "Prevention of hepatitis A through active or passive immunization: recommendations of the advisory committee on immunization practices (ACIP)," The MMWR Recommendations and Reports, vol. 45, pp. 1-30, 1996.

[31] European Association for the Study of the Liver, "EASL clinical practice guide lines: management of chronic hepatitis B," Journal of Hepatology, vol. 10, no. 2, pp. 227-242, 2009.

[32] A. S. F. Lok and B. J. McMahon, "Chronic hepatitis B: update 2009," Hepatology, vol. 50, no. 3, pp. 661-662, 2009.

[33] Y. F. Liaw, N. Leung, J. H. Kao et al., "Asian-Pacific consensus statement on the management of chronic hepatitis B: a 2008 update," Hepatology International, vol. 2, no. 3, pp. 263-283, 2008.

[34] J. C. Teran, T. F. Imperiale, K. D. Mullen, A. S. Tavill, and A. J. McCullough, "Primary prophylaxis of variceal bleeding in cirrhotics: a cost-effectiveness analysis," Gastroenterology, vol. 112, no. 2, pp. 473-482, 1997.

[35] A. I. Sharara and D. C. Rockey, "Gastroesophageal variceal hemorrhage," New England Journal of Medicine, vol. 345, no. 9, pp. 669-681, 2001.

[36] A. Luca, G. D’Amico, R. La Galla, M. Midiri, A. Morabito, and L. Pagliaro, "TIPS for prevention of recurrent bleeding in patients with cirrhosis: meta-analysis of randomized clinical trials," Radiology, vol. 212, no. 2, pp. 411-421, 1999.

[37] P. Ginès and A. Cárdenas, "The management of ascites and hyponatremia in cirrhosis," Seminars in Liver Disease, vol. 28, no. 1, pp. $43-58,2008$.

[38] P. Tandon and G. Garcia-Tsao, "Bacterial infections, sepsis, and multiorgan failure in cirrhosis," Seminars in Liver Disease, vol. 28, no. 1, pp. 26-42, 2008.

[39] M. Rössle, A. Ochs, V. Gülberg et al., "A comparison of paracentesis and transjugular intrahepatic portosystemic shunting in patients with ascites," New England Journal of Medicine, vol. 342, no. 23, pp. 1701-1707, 2000.

[40] J. Córdoba and B. Mínguez, "Hepatic encephalopathy," Seminars in Liver Disease, vol. 28, no. 1, pp. 70-80, 2008.

[41] V. Arroyo, J. Fernandez, and P. Ginès, "Pathogenesis and treatment of hepatorenal syndrome," Seminars in Liver Disease, vol. 28, no. 1, pp. 81-95, 2008.

[42] M. Sherman, K. M. Peltekian, and C. Lee, "Screening for hepatocellular carcinoma in chronic carriers of hepatitis B virus: incidence and prevalence of hepatocellular carcinoma in a North American urban population," Hepatology, vol. 22, no. 2, pp. 432-438, 1995.

[43] E. B. Keeffe, "Liver transplantation: current status and novel approaches to liver replacement," Gastroenterology, vol. 120, no. 3, pp. 749-762, 2001.

[44] E. C. Seaberg, S. H. Belle, K. C. Beringer, J. L. Schivins, and K. M. Detre, "Liver transplantation in the United States from 1987-998: updated results from the PITT-UNOS liver transplant registry," in Clinical Transplants 1998, J. M. Cecka and P. I. Terasaki, Eds., pp. 17-37, UCLA Tissue Typing Laboratory, Los Angeles, Calif, USA, 1999.

[45] D. Shouval and D. Samuel, "Hepatitis B immune globulin to prevent hepatitis B virus graft reinfection following liver transplantation: a concise review," Hepatology, vol. 32, no. 6, pp. 1189-1195, 2000.
[46] R. P. Perrillo, E. R. Schiff, G. L. Davis et al., "A randomized, controlled trial of interferon alfa-2b alone and after prednisone withdrawal for the treatment of chronic hepatitis B," New England Journal of Medicine, vol. 323, no. 5, pp. 295-301, 1990.

[47] D. K. H. Wong, A. M. Cheung, K. O’Rourke, C. D. Naylor, A. S. Detsky, and J. Heathcote, "Effect of alpha-interferon treatment in patients with hepatitis B e antigen-positive chronic hepatitis B: a meta-analysis," Annals of Internal Medicine, vol. 119, no. 4, pp. 312-323, 1993.

[48] J. H. Hoofnagle, A. M. Di Bisceglie, J. G. Waggoner, and Y. Park, "Interferon alfa for patients with clinically apparent cirrhosis due to chronic hepatitis B," Gastroenterology, vol. 104, no. 4, pp. 1116-1121, 1993.

[49] R. Perrillo, C. Tamburro, F. Regenstein et al., "Low-dose, titratable interferon alfa in decompensated liver disease caused by chronic infection with hepatitis B virus," Gastroenterology, vol. 109, no. 3, pp. 908-916, 1995.

[50] R. J. Fontana, "Management of patients with decompensated HBV cirrhosis," Seminars in Liver Disease, vol. 23, no. 1, pp. 89-100, 2003.

[51] R. Fontana, H. W. L. Hann, R. P. Perrillo et al., "Determinants of early mortality in patients with decompensated chronic hepatitis B treated with antiviral therapy," Gastroenterology, vol. 123, no. 3, pp. 719-727, 2002.

[52] E. R. Schiff, C. L. Lai, S. Hadziyannis et al., "Adefovir dipivoxil therapy for lamivudine-resistant hepatitis B in pre- and postliver transplantation patients," Hepatology, vol. 38, no. 6, pp. 1419-1427, 2003.

[53] E. Schiff, C. L. Lai, S. Hadziyannis et al., "Adefovir dipivoxil for wait-listed and post-liver transplantation patients with lamivudine-resistant hepatitis B: final long-term results," Liver Transplantation, vol. 13, no. 3, pp. 349-360, 2007.

[54] J. L. Dienstag, E. R. Schiff, T. L. Wright et al., "Lamivudine as initial treatment for chronic hepatitis B in the United States," New England Journal of Medicine, vol. 341, no. 17, pp. 12561263, 1999.

[55] C. L. Lai, R. N. Chien, N. W. Y. Leung et al., "A one-year trial of lamivudine for chronic hepatitis B," New England Journal of Medicine, vol. 339, no. 2, pp. 61-68, 1998.

[56] N. W. Y. Leung, C. L. Lai, T. T. Chang et al., "Extended lamivudine treatment in patients with chronic hepatitis $\mathrm{B}$ enhances hepatitis B e antigen seroconversion rates: results after 3 years of therapy," Hepatology, vol. 33, no. 6, pp. 15271532, 2001.

[57] M. I. Allen, M. Deslauriers, C. Webster Andrews et al., "Identification and characterization of mutations in hepatitis B virus resistant to lamivudine," Hepatology, vol. 27, no. 6, pp. 1670-1677, 1998.

[58] M. Melegari, P. P. Scaglioni, and J. R. Wands, "Hepatitis B virus mutants associated with 3TC and Famciclovir administration are replication defective," Hepatology, vol. 27, no. 2, pp. 628633, 1998.

[59] Y. F. Liaw, R. N. Chien, C. T. Yeh, S. L. Tsai, and C. M. $\mathrm{Chu}$, "Acute exacerbation and hepatitis $\mathrm{B}$ virus clearance after emergence of YMDD motif mutation during lamivudine therapy," Hepatology, vol. 30, no. 2, pp. 567-572, 1999.

[60] J. P. Villeneuve, L. D. Condreay, B. Willems et al., "Lamivudine treatment for decompensated cirrhosis resulting from chronic hepatitis B," Hepatology, vol. 31, no. 1, pp. 207-210, 2000.

[61] D. Kapoor, R. C. Guptan, S. M. Wakil et al., "Beneficial effects of lamivudine in hepatitis b virus-related decompensated cirrhosis," Journal of Hepatology, vol. 33, no. 2, pp. 308-312, 2000 . 
[62] F. Y. Yao and N. M. Bass, "Lamivudine treatment in patients with severely decompensated cirrhosis due to replicating hepatitis b infection," Journal of Hepatology, vol. 33, no. 2, pp. 301-307, 2000.

[63] S. Manolakopoulos, S. Karatapanis, T. Elefsiniotis et al., "Clinical course of lamivudine monotherapy in patients with decompensated cirrhosis due to hepatitis BeAg negative chronic HBV infection," American Journal of Gastroenterology, vol. 99, pp. 57-63, 2003.

[64] R. P. Perrillo, T. Wright, J. Rakela et al., "A multicenter United States-Canadian trial to assess lamivudine monotherapy before and after liver transplantation for chronic hepatitis B," Hepatology, vol. 33, no. 2, pp. 424-432, 2001.

[65] F. Y. Yao, N. A. Terrault, C. Freise, L. Maslow, and N. M. Bass, "Lamivudine treatment is beneficial in patients with severely decompensated cirrhosis and actively replicating hepatitis B infection awaiting liver transplantation: a comparative study using a matched, untreated cohort," Hepatology, vol. 34 , no. 2 , pp. 411-416, 2001.

[66] R. J. Fontana, E. B. Keeffe, W. Carey et al., "Effect of lamivudine treatment on survival of 309 North American patients awaiting liver transplantation for chronic hepatitis B," Liver Transplantation, vol. 8, no. 5, pp. 433-439, 2002.

[67] Y. Kitay-Cohen, Z. Ben-Ari, R. Tur-Kaspa, H. Fainguelernt, and M. Lishner, "Extension of transplantation free time by lamivudine in patients with hepatitis B-induced decompensated cirrhosis," Transplantation, vol. 69, no. 11, pp. 23822383, 2000.

[68] Y. F. Liaw, M. Raprapoulou-Glgi, H. Chemquer, S. K. Sann, T. Tanwandee, N. Leung et al., "Efficacy, safety of entecavir versus adefovir In chronic hepatitis B patients with evidence of hepatic decompensation," Journal of Hepatology, vol. 50, p. 505A, 2009.

[69] S. J. Hadziyannis, N. C. Tassopoulos, E. J. Heathcote et al., "Long-tern therapy With adefovir dipivoxil in HBeAgnegative chronic hepatitis B for up to 5 years," Gastroenterology, vol. 131, no. 6, pp. 1743-1751, 2006.

[70] H. Izzedine, V. Launay-Vacher, and G. Deray, "Antiviral druginduced nephrotoxicity," American Journal of Kidney Diseases, vol. 45, no. 5, pp. 804-817, 2005.

[71] C. L. Lai, N. Leung, E. K. Teo et al., "A 1-year trial of telbivudine, lamivudine, and the combination in patients with hepatitis B e antigen-positive chronic hepatitis B," Gastroenterology, vol. 129, no. 2, pp. 528-536, 2005.

[72] E. J. Gane, H. L. Chan, G. Choudhuri et al., "Treatment of decompensated HBV-cirrhosis: results from 2-years randomized trial with telbivudine or lamivudine," Journal of Hepatology, vol. 52, supplement 1, p. S4, 2010.

[73] R. A. De Man, L. M. M. Wolters, F. Nevens et al., "Safety and efficacy of oral entecavir given for 28 days in patients with chronic hepatitis B virus infection," Hepatology, vol. 34, no. 3, pp. 578-582, 2001.

[74] S. Levine, D. Hernandez, G. Yamanaka et al., "Efficacies of entecavir against lamivudine-resistant hepatitis B virus replication and recombinant polymerases in vitro," Antimicrobial Agents and Chemotherapy, vol. 46, no. 8, pp. 2525-2532, 2002.

[75] I. T. Chang, R. G. Gish, R. DcMan et al., "A comparison of entecavir and lamivudine tor HBeAg-positive chronic hepatitis B," New England Journal of Medicine, vol. 345, pp. 1001-1010, 2006.

[76] N. Leung, C. Y. Peng, H. W. Hann et al., "Early hepatitis B virus DNA reduction in hepatitis $\mathrm{B}$ e antigen-positive patients with chronic hepatitis B: a randomized international study of entecavir versus adefovir," Hepatology, vol. 49, no. 1, pp. 7279, 2009.

[77] D. J. Tenney, R. E. Rose, C. J. Baldick et al., "Long-term monitoring shows hepatitis $B$ virus resistance to entecavir in nucleoside-naïve patients is rare through 5 years-of therapy," Hepatology, vol. 49, no. 5, pp. 1503-1514, 2009.

[78] A. O. Shakil, L. Lilly, P. Angus et al., "Entecavir reduces viral load in liver transplant patients who failed prophylaxis or treatment for hepatitis B," Journal of Hepatology, vol. 34, abstract 619A, 2001.

[79] J. H. Shim, H. C. Lee, K. M. Kim et al., "Efficacy of entecavir in treatment-naïve patients with hepatitis B virus-related decompensated cirrhosis," Journal of Hepatology, vol. 52, no. 2, pp. 176-182, 2010.

[80] Y. S. Seo, F. S. Jung, J. H. Kim et al., "Lamivudine versus entecavir in patients with hepatitis B virus related decompensated liver cirrhosis," Journal of Hepatology, vol. 50, abstract 550A, 2010.

[81] A. M. Peilirelli, G. Barbarim, M. Romano, C. Furlan, A. Paffettl, and R. Villam, "Entecavlr therapy tor lamlvudme resistant $\mathrm{HBV}$ cirrhotic patients waiting tor OLT: viral, biochemical outcomes at one year," Journal of Hepatology, vol. 50, abstract S14A, 2009.

[82] Y. F. Liaw, C. Lee, U. S. Akarc, P. V. George, F. Wong et al., "Interim results of a double-blind, randomized phase 2 study of the safety of tenofovir disoproxil fumarate, emtricitabine plus tenofovir disoproxil fumarate, and entecavir in the treatment of chronic hepatitis B subjects with decompensated Liver disease," Hepatology, vol. 50, abstract 222, 2009.

[83] C. M. Lange, J. Bojunga, W. P. Hofmann et al., "Severe lactic acidosis during treatment of chronic hepatitis B with entecavir in patients with impaired liver function," Hepatology, vol. 50, no. 6, pp. 2001-2006, 2009.

[84] J. S. James, “Tenofovir approved: broad indication," AIDS Treatment News, no. 373, pp. 2-3, 2001.

[85] J. Heathcote, E. J. Gane, R. A. De Man et al., "Long term (4 year) efficacy and safety of tenofovir disoproxil fumarate (TDF) treatment in HBeAg positive patients with chronic hepatitis B (Study 103): a preliminary analysis," Hepatology, vol. 50, abstract 556A, 2010.

[86] J. Gallant, E. S. Staszewski, A. L. Pozniak, E. Dejesus, M. Sulellnan, M. D. Millel et al., "Efficacy and safety of tenofovir DF vs stavudine in combination therapy in antiretroviralnaive patients: a 3-year randomized trial," Journal of the American Medical Association, vol. 292, no. 2, pp. 191-201, 2004.

[87] J. G. Rajinders, T. Vries-Slulls, B. E. Hansen, H. L. Zaaijer, M. Prinsj, M. Schumen et al., "Five-year tenotovii therapy is associated with maintained virologic response but significant decline in renal function in HIV-HBV infected patients," Hepatology, vol. 50, abstract 506A, 2009.

[88] C. Constable, K. Childs, M. L. Bachon, D. C. Camero, M. R. Mullen, and D. T. Dieterich, "Does tenofovlr increase the risk of abnormal bone and calcium metabolism?" Hepatology, vol. 51, abstract 518, 2009.

[89] E. B. Keeffe, D. T. Dieterich, S. H. B. Han et al., "A treatment algorithm for the management of chronic hepatitis B virus infection in the United States: 2008 update," Clinical Gastroenterology and Hepatology, vol. 6, no. 12, pp. 1315-1341, 2008. 
[90] E. J. Gane, P. W. Angus, S. Strasser et al., "Lamivudine plus low-dose hepatitis B immunoglobulin to prevent recurrent hepatitis B following liver transplantation," Gastroenterology, vol. 132, no. 3, pp. 931-937, 2007.

[91] P. Angus, S. Strasser, S. Patterson, G. McCaughan, and E. Gane, "A randomized study to assess the safety and efficacy of adefovir dipivoxil " Hepatology, vol. 46, abstract 238A, 2007.

[92] E. Gane, S. Strasser, S. Patterson, G. McCaughan, and P. Angus, "A prospective study on the safety and efficacy of lamivudine and adefovir prophylaxis in HBsAg positive liver transplantation candidates," Hepatology, vol. 46, abstract 479A, 2007. 


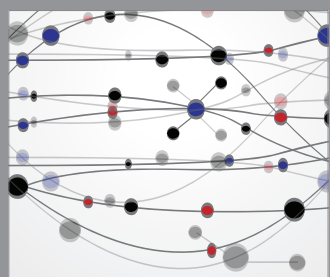

The Scientific World Journal
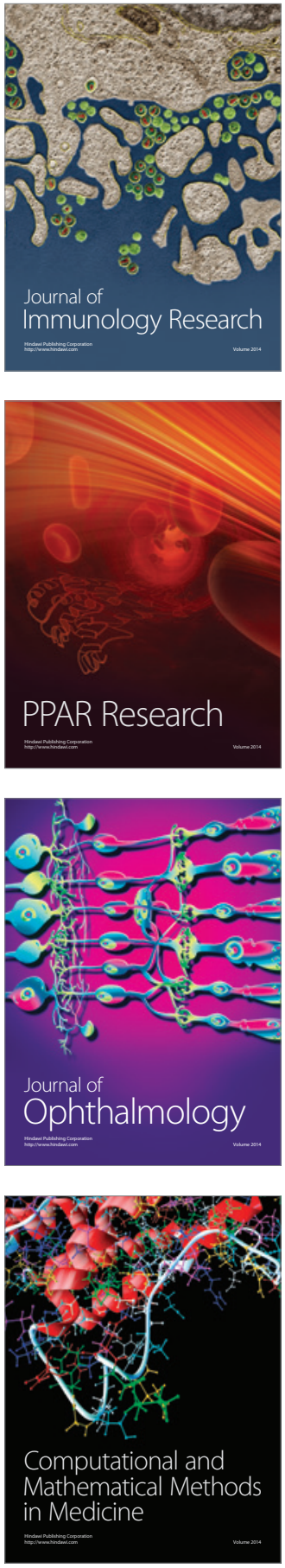

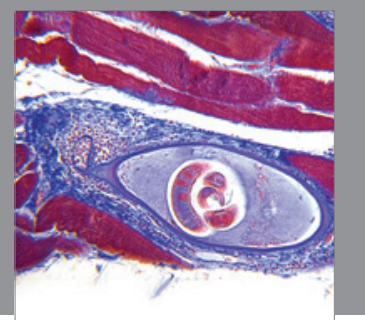

Gastroenterology

Research and Practice
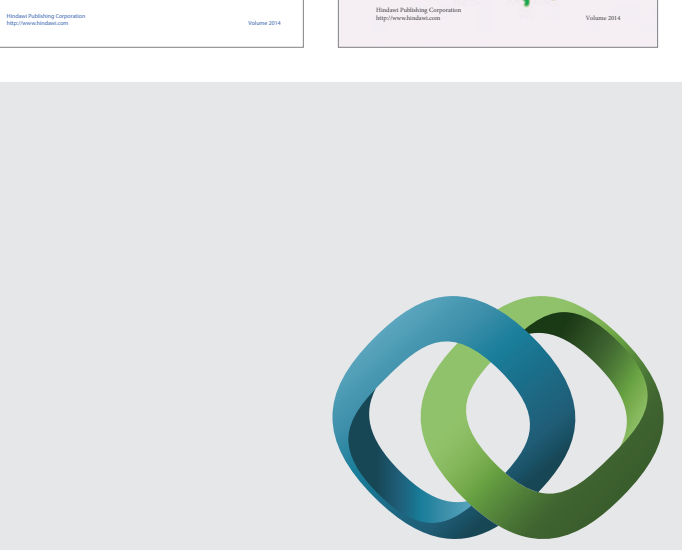

\section{Hindawi}

Submit your manuscripts at

http://www.hindawi.com
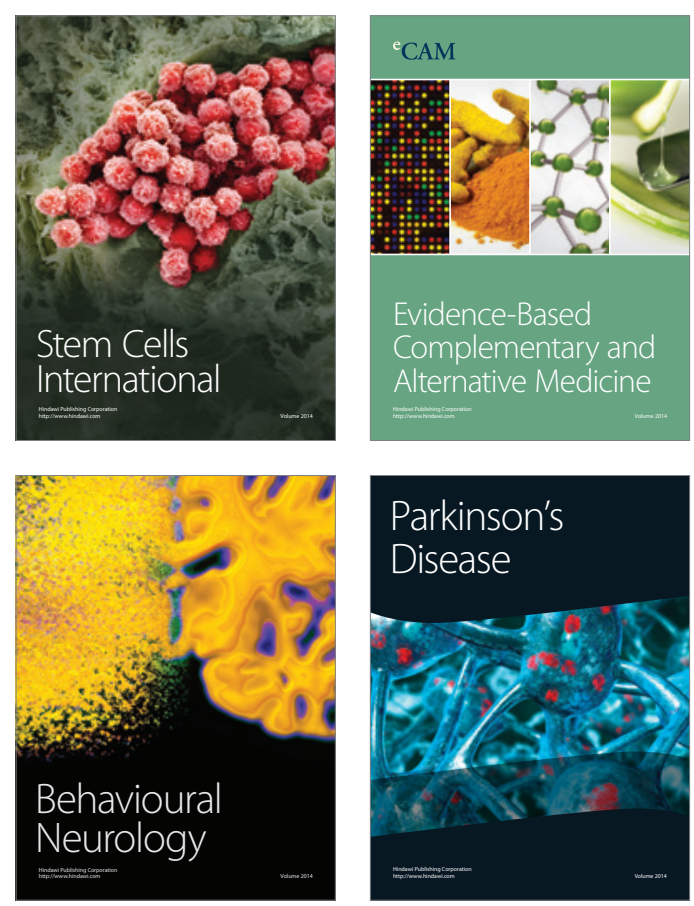

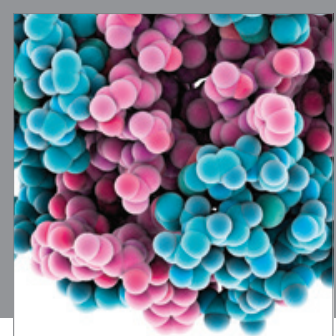

Journal of
Diabetes Research

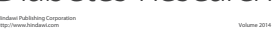

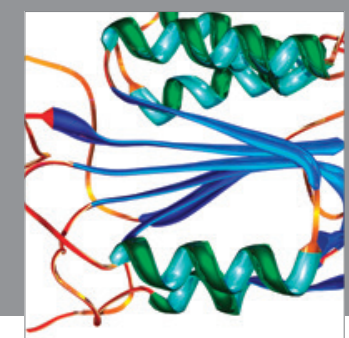

Disease Markers
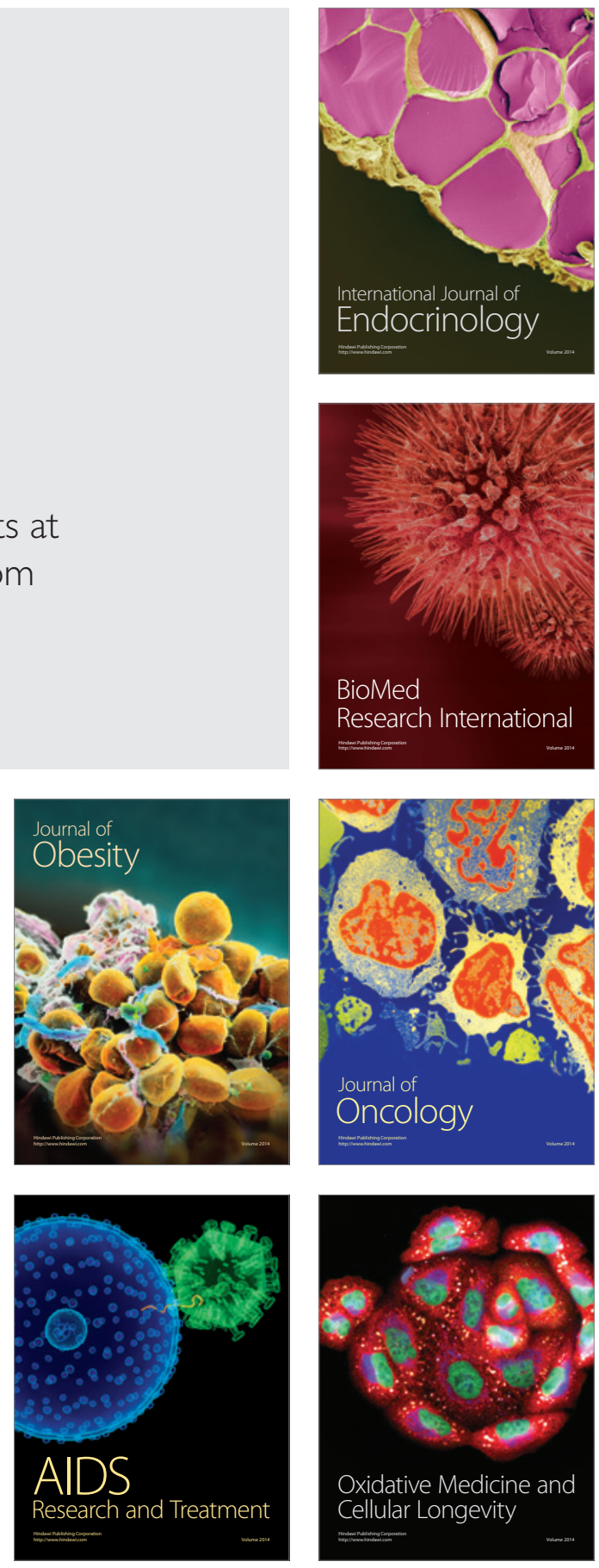